\title{
NIVELES DE UTILIZACIÓN DE LAS FUENTES CLÁSICAS EN LA FIERA, EL RAYO Y LA PIEDRA DE CALDERÓN DE LA BARCA
}

F. JAVIER BRAVo RAMÓN javierbravoramon@gmail.com

\section{RESUMEN}

La primera de las grandes representaciones calderonianas de carácter operístico se inscribe en los hitos del género por la confluencia de sus componentes básicos: el textual, el escenográfico y el musical. Se trata de la primera vez en la que colaboraron Calderón y Baccio del Bianco y sentó las bases de proyectos posteriores. Nos interesa en este artículo analizar de qué forma las referencias clásicas recorren el texto calderoniano, como soporte retórico de las distintas fábulas que se relatan, pero también como eje vertebrador de la historia en sus diversos niveles de utilización.

Palabras Clave: Calderón de la Barca, tradición clásica, representaciones palaciegas, teatro mitológico.

\section{AbSTRACT}

The first of the great Calderonian performances, with operatic characteristics, is etched in history as one of the significant landmark of the genre, because of the confluence of its main components: text, sets and music. It was the first partnership of Calderón and Baccio del Bianco and it laid the foundations for subsequent works. The topic of this article is about the way the classical references run through the Calderonian plays, how the fables form their rhetorical basis and the spine around which the plot and other aspects of the play are built.

KEY WORDS: Calderón de la Barca, classical, royal performances, mythological play. 


\section{UN ARGUMENTO COMPLEJO}

La materia temática sobre la que descansa La fiera, el rayo y la piedra es la mitológica y su argumento, de gran complejidad y estructura elaborada, se podría resumir de la siguiente manera ${ }^{1}$ :

Al tiempo que estalla una gran tormenta, aparecen en escena por partes distintas tres caballeros acompañados de sus respectivos criados, Céfiro y Pasquín, Primaleón y Lebrón, e Ifis y Brunel, quienes al intentar refugiarse en una cueva se encuentran con Irífile, mujer salvaje que aparece vestida con pieles y el cabello suelto. Tras verse acorralada por los hombres, les cuenta que están en Tinacria, junto al palacio de Anajarte, cerca de la fragua de Vulcano y de la gruta en la que viven las Parcas. Después de decirles esto, huye Irífile y los tres hombres salen tras ella, pero no son capaces de alcanzarla. Céfiro revela que es rey de Tinacria y que desea consultar a las Parcas para saber lo que reservan los hados a su reino, por lo cual decide quedarse en los montes e insta a Pigmaleón y a Ifis a que se vayan, pues nada les ata a ese lugar. Ellos se niegan y deciden acompañar a Céfiro a la cueva donde habitan las Gorgonas, que afirman que el eclipse que había tenido lugar acarrea consecuencias distintas para cada uno: para Céfalo una fiera, para Ifis un rayo y para Pigmaleón una piedra. El desconcierto causado por la respuesta es interrumpido por Cupido y su hermano Anteros, que aparecen luchando, uno en defensa del amor absoluto y el otro del amor correspondido. Anteros huye a los dominios de Diana, y los tres jóvenes deciden separarse, junto a sus criados, para buscar a Irífile, no sin antes burlarse de Cupido, que promete vengarse de ellos por tamaño desprecio. El dios desaparece cuando irrumpe en escena Anajarte junto a cuatro ninfas, que cuenta cómo su tío Argante la separó del reino para entregárselo a su hijo Céfalo y la encerró en los palacios donde vive, motivo por el que ella decide vengarse de las dos maneras que tiene a su alcance, aborreciendo a los hombres y cazando a brutos y fieras. Al oír que en los montes se esconden dos fieras humanas, decide cazarlas valiéndose de la música. Las ninfas cambian momentáneamente sus armas por los instrumentos y entonan una canción que provoca la aparición de Irífile, que cae en la trampa que le ha tendido Anajarte. Las dos mujeres, cuando están a punto de comenzar la lucha, son separadas por Céfalo e Ifis, que irrumpen en el escenario y se ponen cada uno del lado de una mujer, con lo que el enfrentamiento se realiza por partida doble, hasta que aparece Anteo, padre de Irífile, y se la lleva a los montes de nuevo. Sale en su búsqueda Anajarte y cuando intentan hacerlo Céfalo e Ifis les detiene durante un tiempo Primaleón, que al preguntarles por lo sucedido recibe como respuesta que temen que el anuncio de las Parcas se haya cumplido. Cuando intenta averiguar más, salen los dos y se queda Primaleón acompañado de su criado Lebrón, que comienzan a oír un ruido de martillazos procedente de la fragua de Vulcano, acompañado de un canto que anuncia que las armas de amor se labran en los talleres de los rayos, las fieras y las piedras. Primaleón decide averiguar lo que sucede y se adentra en las selvas. Aparecen Venus y Cupido y la diosa pregunta a su hijo por qué quiere mezclar el oro y el plomo para causar amor y olvido a un tiempo, a lo que el dios niño contesta que busca que le teman tanto por lo bueno como

${ }^{1}$ Nuestro análisis lo realizaremos a partir de la magistral edición crítica que realizó Aurora Egido, editada en 1989 por Cátedra. 
por lo malo. Venus le reprocha el trato que dio a Anteros, al que alejó de su presencia y la respuesta de Cupido es interrumpida por la llegada de Anteo, que aparece llevando en brazos a su hija Irífile, y pide ayuda al dios, que le defiende de quienes quieren apresarle, los cuales piden que les sean entregados los salvajes, sin atender que están bajo la protección divina, lo que ofende por segunda vez a Cupido, que decide esparcir por el viento sus flechas de amor, con los efectos consabidos. Tras salir todos, tiene lugar un nuevo enfrentamiento entre Cupido y Anteros, en el que uno promete deshacer lo que el otro haga y se citan para la batalla inminente, con lo que se cierra la primera jornada.

La segunda se abre con los lamentos de Primaleón y las burlas de su criado Lebrón, que le acusa de estar enamorado al no querer retirarse de los umbrales del jardín de Anajarte. Aparecen en escena Céfiro y su criado Pasquín y los dos caballeros conversan sobre el motivo que les trajo a esos montes. Primaleón desvela su identidad de escultor y relata el suceso que le aconteció cuando quiso vender un mármol, hasta que es interrumpido por la aparición de Anajarte, que les pregunta qué es lo que buscan allí, pero les impide contarlo hasta el final la irrupción de Ifis y su criado Brunel, que traen a Irífile, a la que Anajarte decide tomar a su servicio y desdeñar las peticiones de los tres hombres, a los que cierra las puertas del jardín. Céfiro e Iris retoman la disputa que surgió entre ellos cuando quisieron ayudar a las dos damas, y Primaleón se interpone entre ambos para impedir que luchen, a pesar de que descubre que Ifis es el príncipe que le salvó la vida tiempo atrás. La disputa hace que Anajarte salga de nuevo acompañada de sus damas para preguntar qué sucede, a lo que Pasquín responde que es pugna de locos. El relato vuelve a ser interrumpido por la llegada de Isbella que cuenta cómo Irífile, al verse reflejada en un espejo, se ha creído dueña de todo lo que la rodeaba. Anajarte decide que vuelvan al jardín para que la música calme los sentimientos de la joven. Lebrón queda con las cuatro acompañantes, y al preguntar cuál de ellas quiere ser su enamorada recibe por respuesta la burla y el plantón de las damas. Reaparece Primaleón, que entra en el jardín, al igual que hace su criado tras oír las voces de Cupido, que se jacta de su victoria sobre los tres hombres y se dispone a ver y oír la representación del triunfo, cual si fuera un espectador teatral al que acompaña la música. Ifis, Primaleón y Céfiro se esconden en el jardín, mientras que Lebrón es incapaz de hacerlo. Aparecen Anajarte, Irífile y las cuatro damas y descubren al instante al criado, que es prendido y condenado a morir en el lago de las focas, aunque recibe la ayuda de Isbella. La escena se convierte en un espacio teatral dentro del teatro con focos de atención múltiples: por un lado las palabras de las damas, por otro las voces de los caballeros escondidos, a cuyas dos estampas sonoras acompañan las canciones, y todo ello comentado de forma burlesca por el espectador cómico Lebrón. La armonía de la escena es rota por la aparición de Anteo, que llega en busca de su hija, aun a costa de la vida de Anajarte, la cual, al pedir ayuda, hace que salgan de su escondite los tres caballeros, con lo que se vuelve a crear confusión, al querer unos salvar a los que los otros desean herir, ante las miradas de los terceros, que pretenden mediar. Las disputas las resuelve Anajarte haciendo que todos salgan de su jardín con un pretexto distinto: a Ifis le conmina a volver a su barco, a lo que él accede aunque promete volver; a Irífile la expulsa de su servicio, con lo que su padre puede rescatarla y Céfiro puede volver a perseguirla por los montes; y hace también que saquen del jardín la estatua de la que Primaleón está enamorado. Al quedarse sola, Anajarte se pregunta si alguien la volverá a requerir de amores, a lo que contesta Anteros que sí y la insta a 
querer: Pero ella sigue obstinada en su decisión, a pesar de las advertencias del dios, que recuerda que el rayo se convierte en piedra al morir.

La tercera jornada se inicia con el diálogo entre Céfiro y Primaleón, en el lugar en el que este último construye un palacio para llevar allí la estatua de la que está enamorado. Al quedarse sólo con su criado Lebrón, discute con él y a causa de los gritos sale Anajarte y cuenta cómo sacó la estatua de su jardín y la mandó llevar al monte, hacia donde sale corriendo Primaleón. Entran en escena Laura e Isbella y cuentan que de las montañas y el mar llegan las voces de gente que se acerca, y al poco rato aparece Ifis, que ha retornado a la isla con un ejército, para vengar el encierro al que Céfiro y Argante someten a Anajarte, quien acepta el ofrecimiento por el valor que encierra la propuesta, aunque no por el amor. A Ifis se le une Anteo, que revela que, cuando le usurparon el trono a Anajarte huyó para vivir como un salvaje hasta que pudiera restaurar el derecho de la que para él es su reina. Salen ambos y al preguntar Isbella y Laura a su señora qué hará cuando vuelva Ifis vencedor, contesta ella que no pagará con Amor, a pesar de que en el aire se oye la voz de Anteo que afirma lo contrario. Entretanto Céfalo es cogido en una emboscada con el reclamo del nombre de Irífile, que al darse cuenta de la estratagema utilizada por su padre decide ayudar al joven y le entrega una espada para que huya, con lo que la persecución vuelve a comenzar. A continuación, aparecen en escena Venus y sus dos hijos, Cupido y Anteros, acompañados cada uno de un coro de música, que exponen sus respectivos argumentos. Tercia en la disputa Venus, que unifica lo que ambos coros cantan. La escena nos lleva a continuación al lugar en el que los tres criados de los caballeros cambian impresiones sobre las locuras de sus amos, hasta que son interrumpidos por la llegada de Primaleón, que trae la adorada estatua a su palacio. Se oyen de nuevo voces que anuncian guerra y recuerdan la persecución de Céfiro. Primaleón, al oírlas, sale para averiguar lo que ocurre y vuelve llevando en los brazos a Anajarte, a la que deja al cuidado de Lebrón y torna a salir. Cuando ella recobra el sentido ve la estatua que estaba en su jardín y se reafirma en la decisión de no amar a nadie, para así no ser amada ella, como le sucede al mármol que le perteneció.

Aparecen en escena todos e Ifis entrega a Céfiro, al que ha apresado, como prometió. Anajarte lo agradece aparentemente, aunque tenga resuelto asesinarle después según revela, lo que no podrá cumplir ya que se va convirtiendo gradualmente en estatua ante el estupor de todos. Ifis decide seguir amando a Anajarte, a pesar de su conversión en mármol, al igual que hizo Primaleón, que es recompensado con la transformación en mujer de la estatua a la que adoraba. Céfiro, a su vez, consigue que Anteo le entregue a su hija, y no ya como fiera, pues según relata el padre de la joven es la reina heredera de Tinacria, a la que cambió en la cuna por Anajarte, porque temía la ira del padre de Céfiro. Irrumpen en escena Anteros, Cupido y Venus, que cantan la victoria del Amor correspondido, con lo que termina la obra y se da paso a la máscara final.

\section{El MUNDO DE LOS HUMANOS}

En la obra se superponen dos mundos con sus respectivas historias, el de los humanos y el de los dioses, que aunque operan en niveles distintos, confluyen al final de forma 
calculada, sin apenas mezclarse, en un ejemplo de armonía que ordena el caos inicial y que encontramos en otros textos de Calderón.

En el plano de los personajes no divinos nos encontramos con tres parejas de amo y criado, que se complicarán al añadir el elemento amoroso al que se entrega cada uno de los caballeros sobre los que Cupido lanza sus flechas de oro, que serán de plomo en el caso de las mujeres. Por tanto, podemos hablar de Pigmaleón/ Lebrón/ estatua; Céfiro/ Pasquín/ Irífile; e Ifis/ Brunel/ Anajarte.

El carácter híbrido de las fuentes calderonianas se hace evidente en estos tríos, pues si bien los criados se sitúan en la órbita de los graciosos típicos de la Comedia Nueva, y adquieren nombres que remiten a supuestas cualidades que podríamos asociar con sus características de servidores (herederos de la Commedia dell'Arte y tamizados por la tradición teatral hispana), y a reminiscencias de escuderos y caballeros medievales, en el caso de las parejas de enamorados la fuente es clásica, de forma directa en dos de ellas e indirecta en la tercera.

Si rastreamos la procedencia de las historias de las que parte Calderón debemos acudir a la Philosofía secreta de Pérez de Moya, en concreto al último de los capítulos del Libro IV titulado De la significación de algunas fábulas en suma, por causa de brevedad, para comprobar que los relatos de Pigmaleón y la estatua y Najarte e Ifis aparecen casi seguidos, separados tan sólo por la lectura moral de la historia de Céfalo y Procris, que por otro lado utilizó Calderón como fuente en más de una ocasión².

\section{Primaleón y la estatua}

Pérez de Moya, como señala en el título del capítulo apuntado, se detiene en el significado o aspecto moral del relato y no tanto en la narración de los hechos:

«La fábula de Pigmalión, nos amonesta haber algunos que aman cosas de poco momento, sólo por su contento, como son pinturas, medallas y cosas semejantes; las cuales aman con tanto ardor, que las mismas cosas satisfacen a sus deseos. [...] Amonestamos esta historia en decir, que aborreciendo Pigmalión las mujeres, criase mujer para casarse con ella, que muchos aunque aborrecen el pecado, le aman y se están en él. ${ }^{3} »$

Evidentemente la lectura que realiza Pérez de Moya parte de la fábula original, en la que Pigmalión decide buscar a la mujer perfecta para casarse con ella y, frustrado por no encontrarla, se retira a crear esculturas para compensar su fracaso. Esculpe entonces una tan hermosa, a la que pone el nombre de Galatea, y de la que se enamora, como podemos leer en el Libro X de Metamorfosis de Ovidio.

Nos parece interesante como ejemplo de los caminos que solían recorrer las fábulas, al ser utilizadas por autores de épocas distintas, en géneros diversos y con motivaciones

\footnotetext{
${ }^{2}$ En concreto escribió una comedia burlesca que llevaba el título de los dos personajes, Céfalo y Procris, y la que se considera primera ópera española de la que se conserva la música íntegra, Celos aun del aire matan.

3 PÉrez de Moya, 1995: 564.
} 
dispares, transcribir los relatos de Ovidio y la correspondiente traducción/versión de Jorge Bustamante para compararlos con el de Calderón. Comenzamos con el clásico latino:

«Pigmalión las había visto vivir [a las Propétides] en perpetua ignominia, y, disgustado por los innumerables vicios que la naturaleza ha puesto en el alma de la mujer, vivía solo y sin esposa, y llevaba ya mucho tiempo desprovisto de consorte. Por entonces esculpió con admirable arte una estatua de níveo marfil, y le dio belleza como ninguna mujer real puede tener, y se enamoró de su obra. El rostro es el de una joven auténtica, de quien se hubiera creído que vivía y que deseaba moverse, si no se lo estorbara su recato: hasta tal punto el arte está escondido por obra del propio arte. La admira Pigmalión y apura en su corazón el fuego por aquel ficticio. Muchas veces aproxima a la obra sus manos, que la palpan para comprobar si aquello es un cuerpo o es marfil, y aun no se resuelve a admitir que sea marfil. Le da besos y cree que ella se los devuelve y le habla y la coge, y le parece que sus dedos oprimen los miembros que tocan, y teme que se amoraten las carnes que él aprieta, y ya le dirige palabras acariciantes, ya le lleva regalos gratos a las jóvenes, conchas y torneadas piedrecitas y pajaritos y flores de mil tonos y lirios y pelotas de colores y lágrimas caídas del árbol de las Heliades; le adorna también con ropas los miembros, le pone piedras preciosas en los dedos, le pone un largo collar en el cuello; de las orejas le cuelgan ingrávidas perlas, del pecho cadenillas. Todo le sienta bien; pero tampoco desnuda resulta menos hermosa. La tiende en un lecho de ropas teñidas por la concha de Sidón, y la llama compañera de su tálamo, y reclinándole el cuello lo hace reposar en medio de blandas plumas, como si ella lo fuera a notar. Había llegado el día de la fiesta de Venus, el más celebrado en toda Chipre, y habían caído, golpeadas en la nívea cerviz, vacas con amables cuernos recubiertos de oro, y humeaba el incienso, cuando Pigmalión, después de realizar su ofrenda, se colocó junto al altar, y empezando tímidamente: 'Si los dioses podéis darlo todo, yo anhelo que mi esposa sea...' Y no atreviéndose a decir 'la joven de marfil', dijo 'semejante a la joven de marfil'. La áurea Venus, que asistía en persona a sus fiestas, comprendió lo que significaba aquella súplica, y, como augurio de su favorable voluntad, por tres veces se encendió la llama y levantó por el aire la punta. Cuando volvió Pigmalión, va en busca de la imagen de su amada, e inclinándose sobre el lecho le dio besos: le pareció que estaba tibia; le acerca de nuevo los labios, y también con las manos le palpa los pechos: el marfil, al ser palpado, se ablanda, y despojándose de su rigidez cede a la presión de los dedos y se deja oprimir, como la cera del Himeto se reblandece al sol, y moldeada por el pulgar se altera adquiriendo múltiples conformaciones, y es el propio uso el que la hace útil. Él se queda atónito y vacila en regocijarse y teme ser víctima de una ilusión, y entretanto, inflamado de amor, vuelve una y otra vez a tocar con las manos el objeto de sus ansias. ¡Era un cuerpo! Laten las venas palpadas por los dedos. Entonces es cuando el de Pafos pronuncia palabras elocuentes con las que quiere dar gracias a Venus, y oprime con sus labios, labios al fin verdaderos, y la joven sintió que se la estaba besando y se ruborizó, y levantando tímidamente los ojos y dirigiéndose a los de él, vio, a la vez que el cielo, a su amante. A la boda que era su obra asiste la diosa, y cuando ya por nueve veces se habían juntado los cuernos de la luna formando el disco completo, dio ella nacimiento a Pafos, de la cual ha tomado la isla este nombre.»

Por lo que respecta a la versión de Bustamante sobre el texto de Ovidio llama la atención, a pesar de su carácter moralista, la presencia del elemento sensual, que de alguna forma, causa un efecto contrario al que supuestamente busca el autor:

«Cuando Pigmalión vio que aquellas mujeres [las Propétidas] por tan sucio pecado de lujuria eran tornadas en piedras estériles, hubo gran ira contra ellas, y de allí adelante aborreció toda compañía de mujeres, jurando de tarde o nunca casarse con ninguna mujer, por esta 
causa hizo una imagen de marfil en figura de mujer, y tan maravillosamente la entretalló, que parecía viva, en tanta manera que cuanto más la miraba, tanto más perfecta le parecía y más se enamoraba de ella. A las veces pensaba mirándola que cierto estaba viva y se movía; otras la abrazaba y besaba y hablaba con ella, como si fuera mujer animada, muchas veces la halagaba y metía sortijas en los dedos, y en la garganta collares y cadenas de oro; y haciéndole esto tentábale el cuerpo con las manos y dedos, como si fuera de carne; después vestíale paños de seda, púrpura y brocado, porque le pareciese más hermosa; después la echaba en la cama y echábase con ella y hablábale como si fuera su mujer. En aquellos días, viniendo la fiesta de Venus, en la cual todas las gentes varones y mujeres se aderezaban para hacer sacrificios y holocaustos a Venus, Pigmalión entre los otros fue con sus sacrificios a rogar a los dioses que tornasen aquella imagen de marfil, en mujer de carne y huesos. Venus oyendo las oraciones suyas, una antorcha que tenía Pigmalión en las manos muerta se le encendió, y allí entendiendo el que su ruego era oído tornóse luego para su casa, y demandó la imagen de alabastro, y parecióle que había algunas señales de vida más que antes, y hallándola más que nunca sudando, echóse con ella en la cama, donde la abrazaba y la besaba y la tentaba los pechos y tetas con las manos, y parecíale que las hallaba más blandas. Estando tentándola por muchas partes, fue poco a poco enterneciéndose el alabastro, y tomando forma de carne, y a poco de rato fue tomando en forma de mujer viva. Cuando Pigmalión vio que tenía mujer animada, dio gracias y sacrificios a Venus: de aquel día adelante vivió muy alegre con su mujer, a quien amorosamente besaba, abrazaba y holgaba con ella, y ella con él, y comunicaban el uno con el otro todas sus haciendas. Ellos hicieron luego sus bodas y Venus fue la que en estas bodas les vino a hacer muy grandes fiestas y honras. La novia fue luego preñada, y a su tiempo parió un hijo que había nombre Pafo, de quien después tomó el nombre aquella isla donde ellos moraban. ${ }^{4} \gg$

Por lo que respecta al tratamiento que Calderón resalta de la fábula de Pigmalión es evidente que no es comparable en su totalidad, pues no se trata más que de una de las tres historias que se desarrollan en el texto dramático, que además comparte protagonismo temático con la disputa entre los dos dioses hermanos. Pero aun así, por los fragmentos que podemos entresacar inferimos que en La fiera... se resalta como una de las características principales el aspecto relacionado con la creación artística, tan del gusto calderoniano y que aparece en Ovidio ${ }^{5}$ y no tanto en Bustamante. Así, cuando Céfiro oye el nombre de su compañero, le pregunta sorprendido:
«iSois vos aquel a quien dieron
la pintura y la escultura
tanta opinión, que es proverbio
decir de vos que partís
con Júpiter el imperio
de dar vida y de dar alma
así al metal como al lienzo? ${ }^{6} »$

La respuesta que le da Pigmalión incide en el motivo que le obligó a abandonar su patria, que fue el desprecio que un deudo del rey hizo al valor de una de sus obras y cuyas consecuencias no llegamos a conocer del todo, pues la acción dramática de la obra

\footnotetext{
4 Bustamante, 1595, Libro X: 156-157.

5 Recordemos parte del verso 252: «ars adeo latet arte sua», y que Ruiz de Elvira tradujo, como ya hemos reflejado: «Hasta tal punto el arte está escondido por obra del propio arte.»

${ }_{6}$ Vv. 1471-1477. Egido, 1989: 243-244.
} 
la deja Calderón en suspenso, desplazando la atención a otro foco de interés distinto. El hecho de primar el plano artístico sobre otros se observa también en las décimas siguientes, que inciden en la capacidad de la creación del escultor para dar vida a una obra de mármol, a cuya humanidad tan sólo le falta el alma para alcanzar la plenitud:

«Ya que sólo a verte llego helada, muda hermosura, permite que mi locura temple en sus aguas su fuego.

Desde el instante que, ciego, vi en tu rara perfección lograda mi admiración, te confieso que, al mirarte, es la inclinación del arte arte de toda inclinación. ¿Qué mano hoy, imagen bella, de deidad te retrató tan superior que copió hasta el influjo a tu estrella?

$\mathrm{Y}$ es verdad que, a estar sin ella, ¿quién inclinarme podía a amar, si ya no sería que al ver cuán perfecta estás que alma te falta, no más te has valido de la mía? La elección estimo; no duren tus ansias esquivas que, a precio de que tú vivas, ¿qué importa que muera yo? $Y$ pues mi efecto te dio el alma, ;oh estatua bella!, ¡vive! ¡vive al poseella!, porque no es justo (¡ay de mí!) que ella no te sirva a ti y a mí me dejes sin ella. O para verme y hablarme el alma que te di emplea, o para que te hable y vea vuelve, volviendo a animarme, el alma que te di, a darme. Mira que es desdén indigno si a ti fue y a mí no vino creer que algún tirano dios poniéndose entre los dos nos la ha hurtado en el camino. ${ }^{7} »$

\footnotetext{
7 Vv. 2130-2169. Egido, 1989: 281-282.
} 


\section{La negativa a amar de Anajarte}

La fábula de Anajarte e Ifis es sometida en el texto de Calderón a un cambio parcial del desenlace, referente a la muerte del personaje masculino, que en el original reflejado en Metamorfosis se suicidaba como venganza por el desprecio al amor no correspondido por parte de su amada, la cual era transformada en estatua por Venus. Ovidio lo relata de la siguiente manera:

«Conmovida sin embargo, dijo: 'Veamos el triste entierro', y entró en el piso alto de la casa, que tenía amplias ventanas, y apenas llegó a ver bien a Ifis colocado en el ataúd, los ojos se le quedaron yertos, la sangre caliente huye de su cuerpo, que adquiere un tinte pálido, e intentando volver el rostro tampoco pudo hacerlo, y poco a poco le va invadiendo los miembros la piedra que desde mucho antes estaba en su corazón.»

Nos interesa aún más el fragmento que se sitúa a continuación, por su carácter evemerista, en el que Calderón también incurre, como veremos más adelante, aunque con una mirada satírica, muy típica de una de las interpretaciones del mito clásico durante el barroco:

«Y para que no creas que se trata de una ficción, Salamina conserva aún una estatua que representa a la dama, y posee también un templo bajo la advocación de Venus Mirando.»

Y cierra la fábula con un consejo a la dama a quien iba dirigido el relato:

«Ten presente todo esto, querida mía, abandona por favor tu obstinada altanería, y únete, ninfa, a quien te ama: y que así ni una helada primaveral te queme los frutos nacientes, ni rápidos vientos los arranquen cuando aún están en flor. ${ }^{8}$ ”

La versión de Bustamante no difiere apenas de su original, aunque suprime el final que hemos apuntado, más allá de un «y allí quedó por memoria», en alusión a la transformación de Anajarte.

En cuanto a la variante de Calderón, mejora de forma evidente el momento de la metamorfosis de la mujer en estatua, cuyo efecto debió de reforzar su espectacularidad textual con la interpretación de la actriz que al ritmo gradual y entrecortado del texto calderoniano, con el doble foco que permitían los apartes insertos en los propios versos, se fue inmovilizando hasta dar la apariencia de mármol, para lo cual se debió de ayudar del vestuario9 ${ }^{9}$ Veamos los versos de Calderón:
«Agradecida (¿qué importa
que afable este rato esté,
si por no verme obligada
sabré matarle después,
o pésele o no le pese
a Anteros, el amor fiel?)
a tu valor (¡ay de mí!)
Ifis generoso (¿Qué

\footnotetext{
8 Metamorfosis, 2008: 4001-401.

${ }_{9}$ En la edición impresa en 1687 por Vera Tassis encontramos una acotación que dice: «Queda vestida de blanco como la Estatua.»
} 
mortal frío me estremece?), confieso (¿qué ansia cruel, la voz me hiela en el labio?) que debo (;letargo infiel es el que siento!) a tu fama (¡qué ira!) el sagrado laurel y la vida. Pero miento, pero miento, que no fue (un áspid tengo en el pecho, en la garganta un cordel) la vida la que te debo porque no puedo deber lo que no tengo (¿ay de mí!). ${ }^{10}{ }{ }^{\prime}$

La lectura moralista la encontramos en la Philosophia secreta de Pérez de Moya, quien nos dice que

«por la fábula de la muerte de Ifis, por causa de Anaxárete, nos amonestan cuán vehementes son las llamas de amor, y la bondad de algunas mujeres, que con ninguna cosa se encienden sus corazones por guardar castidad más que si fuesen una piedra. ${ }^{11}{ }_{\text {» }}$

\section{El mundo salvaje}

La tercera de las historias entrelazadas, con personajes humanos como protagonistas, no se basa en una fuente clásica directa, aunque sí podamos buscar relaciones en algunos de los personajes implicados. La historia del rey que usurpa el trono y hace que su legítimo gobernante viva como un salvaje recluido en los montes es recurrente en la producción calderoniana, pues la abordó en varias ocasiones, bien para marcar la capacidad humana para poder elegir gracias al libre albedrío, bien para resaltar la oposición entre el mundo civilizado y el primitivo, que es el que se resalta en el caso de La fiera...

Aunque no podamos encontrar relaciones claras entre Céfiro e Irífile con el mundo clásico, más allá de lo puramente nominal, sí las podemos rastrear en la figura del padre de la joven, Anteo, relacionado con Hércules, y del que Pérez de Moya dice, entre otras cosas lo siguiente:

«Andando Hércules por diversas partes del mundo, vino a tierra de Libia, donde moraba Antheo, hijo de la Tierra, nacido sin padre; era gran luchador, que con cuantos probaba sus fuerzas derribaba; y tenía tal propiedad que si caía alguna vez o se dejaba de industria caer en la tierra se levantaba con tanta fuerza, y así al fin no podía quedar vencido; y a los que vencía, tomaba él, como era Gigante, y bajaba los grandes árboles, y poníalos allí, y luego dejaba el árbol, y lanzábalos muy lejos. ${ }^{12}{ }$

\footnotetext{
10 Vv. 3819- 3839. Egido, 1989: 385-386.

11 Pérez de Moya, 1995: 563.

12 Pérez de Moya, 1995: 453.
} 
De la fábula de Anteo se llegan a dar tres interpretaciones distintas: la primera como declaración histórica, la segunda del aspecto moral de la historia y la tercera de su sentido natural. Esta última reseña lo siguiente:

«Algunos quisieron entender por esta fábula la generación de las plantas; por Hércules entendieron el Sol; por Antheo las simientes. Éstas, tocando a la tierra estando sembradas, por virtud del Sol reciben y se levantan en alto con mayores fuerzas, y vienen a fructificación. ${ }^{13}$ »

Céfiro, como ya dijimos, no parece que tenga relación con el viento del oeste de la tradición clásica, y probablemente no sea más que una utilización por parte de Calderón de un nombre sin connotaciones grecolatinas explícitas.

Tampoco parece relacionarse de forma directa la fábula de Erífile con el nombre que se utiliza en La fiera... para caracterizar a la hija de Anteo, Irífile. No obstante, con toda probabilidad, los ecos de dicho nombre, y de la historia ligada a él, formaran parte de la tradición literaria de fuentes clásicas, aunque se reutilizaran de modos diversos por los distintos autores. Erífile se relaciona con el ciclo de los siete contra Tebas y en la Biblioteca atribuida a Apolodoro podemos leer lo siguiente:

«Anfiarao, hijo de Oícles, era adivino y, previendo que todos los que tomaran parte en la expedición excepto Adrasto habían de perecer, rehusaba ir y desanimaba a los demás. Pero Polinices fue ante Ifis, hijo de Aléctor, para saber cómo se podría obligar a Anfiarao a combatir. Ifis le respondió que a condición de que Erífile recibiese el collar. Aunque Anfiarao había prohibido a Erifile aceptar regalos de Polinices, éste le entregó el collar y le pidió que convenciera a Anfiarao para que guerrease. Pues dependía de ella desde que Anfiarao, habiendo disputado con Adrasto, y reconciliado con él más tarde, había jurado que Erífile arbitraría en futuras disensiones. Ahora que Adrasto incitaba a la lucha contra Tebas y Anfiarao se oponía, Erífile, tras admitir el collar, lo hizo marchar contra Adrasto. Forzado así a luchar, Anfiarao encargó a sus hijos que, al hacerse adultos, mataran a su madre y emprendieran una expedición contra Tebas. ${ }^{14}{ }^{»}$

Baltasar de Vitoria recoge la historia en su Theatro de los dioses de la gentilidad, donde podemos leer, entre otras cosas, la lectura misógina convertida en tópico recurrente en las comedias del XVII:

«Y he considerado, como Virgilio puso a Erífile en el número de los amantes, que murieron de amor, habiendo ella tenido tan poco a su marido Anfiarao, pues estimó en más el collar precioso, que a su propio marido, que la honraba, quería y estimaba; pero en tratando las mujeres de galas, no hay otro Dios, ni otro marido. ${ }^{15}$ »

La cita a Virgilio se refiere a la mención que hace el autor latino en la Eneida, que sitúa a nuestro personaje en los Campos de las lágrimas, junto a Fedra y a otro de los personajes clásicos de recorrido calderoniano, Procris: «Ve allí a Fedra y a Procris y a Erifila desolada, mostrando las heridas que recibió de su hijo despiadado. ${ }^{1{ }^{1}{ }}$

Sí tiene un cierto bagaje novelesco el personaje de Erífile, representación de la mujer salvaje, como en el Canto VII del Orlando furioso de Ariosto, donde aparece subida a la

13 Pérez de Moya, 1995: 455.

${ }_{14}$ Biblioteca, Libro III, 6, 2. Apolodoro, 1982: 153.

15 Vitoria, 1702, Libro IV: 488.

16 VIRGILIO, Eneida VI, 444-445. 
grupa de un lobo y es derrotada por Ruggiero; e incluso llega a ocupar el protagonismo de más de una obra, como en la novela pastoril novohispana de Bernardo de Balbuena El siglo de oro en las selvas de Erífile, aparecida en 1608, o en la más antigua Erifile de Leone de Sommi.

El resto de personajes mortales no tienen una relación directa con el mundo grecolatino, más allá de la conexión con la materia argumental a través de las vicisitudes de la acción dramática.

\section{Ni HUMANOS NI DIOSES}

Como puente argumental entre los personajes humanos y divinos de origen clásico se sitúan tres grupos de caracteres mitológicos que participan de manera dispar en el desarrollo argumental.

El primero tiene una presencia única en el texto, pero de gran trascendencia, pues se trata de cuatro versos cantados que no se alejan del tipo de canción popular en seguidilla propia de las comedias de corrales.

El fragmento en cuestión lo pone Calderón en boca de una sirena o de varias, dependiendo de la edición, que pasan cantando, y aunque hemos de ubicar a estos personajes en la tradición de los seres mitológicos marinos y así aparecen en varias obras de Calderón ${ }^{17}$, habría que resaltar la trascendencia que tienen en el mundo de la música y su relación con los personajes a los que nos referiremos a continuación, las Parcas. Pérez de Moya les dedica un artículo completo en su Philosofía secreta y de ellas nos dice, entre otras cosas, lo siguiente:

«Ovidio finge que las Sirenas eran unas doncellas compañeras de Prosérpina, las cuales, después del robo que della hizo Plutón, buscáronla por toda la tierra, y no hallándola, quisieron buscarla por la mar, y subiéndose con este intento a unas altas peñas que estaban a la orilla dél, estuvieron algún tiempo, hasta que después, con el pesar de haber perdido a su compañera Prosérpina, se quisieron despeñar en el mar. Los dioses, habiendo compasión dellas, mudaron sus formas, quedándoles del ombligo arriba de doncellas y de allí debajo de pescado, y los pies de gallina con alas de ave, según dice Alberico y san Isidro. [...] Fingen asimismo cantar tan dulcemente que los marineros que las oyen, admirados de la melodía, adormíanse, y no mirando por sí, las Sirenas, cuando los sienten dormidos, trastornan las fustas para después comer sus carnes, por lo cual los antiguos pintaban las Sirenas tendidas en unos prados verdes, entre huesos de muchos muertos. ${ }^{18}$ 》

Y en la declaración que hace Pérez de Moya sobre las características de las Sirenas, podemos leer algunas afirmaciones como estas:

«Dicen ser hijas de Calíope por declarar que cantaban, porque Calíope es una musa a quien dan la excelencia de cantar ambas entre las musas; y que otros digan ser hijas de Thersícore, no va más desta que de Calíope, porque son musas, y a todas las musas pertenece el deleite del canto; y el saber de Calíope significó sonido o buena plática. Derívase de calon y

${ }^{17}$ En especial habría que mencionar las obras calderonianas relacionadas con la historia de Ulises, como El mayor encanto, amor, y en sobre todo El golfo de las sirenas, aunque también aparezcan las sirenas en otros textos como El jardín de Falerina, la versión escrita por Calderón en colaboración con Rojas Zorrilla y Coello.

18 Pérez de Moya, 1995: 212-213. 
phonos, palabras griegas, que esto significan, y conviene esto a todas las mujeres de esta arte, porque usan de palabras halagüeñas para atraer a los hombres a su torpe vida, con la cual ellas los roban. [...] En lo que se dice que éstas tañían diversos instrumentos y cantaban en voz, denota que las tales su ejercicio es músicas y cantares con que conmueven a lujurias, porque con la dulzura del canto atraen los hombres a su amor. ${ }^{19}$ »

En realidad, las Sirenas no cantan más que fábulas, mitos, como apuntan KahnLyotard y Loraux:

«Epos: ése es el contenido del canto de las Sirenas, aunque aquellos que lo escuchen no lo entenderán por encontrarse demasiado hechizados por la voz que domina el himno. ${ }^{20} \gg$

El segundo grupo de personajes mitológicos que aparecen en el texto presenta un sincretismo nominal característico de la tradición clásica española, pues si bien el nombre colectivo por el que se las conoce es el latino, Parcas, en griego Moiras, se utilizan en la tradición occidental los nombres individuales de Cloto, Láquesis y Átropos y no los de Nona, Décima y Morta, por una cuestión puramente fonética o eufónica, hemos de suponer. Recurrimos de nuevo a Pérez de Moya para saber algo más sobre estos personajes:

«Las Parcas fingen que fueron tres hermanas tan concordes que nunca entre ellas desensión alguna fue oída, como entre los otros dioses. Tenían los antiguos que no sólo no se podía hacer alguna cosa sin la voluntad de las Parcas, mas aun la vida de los hombres estaba en la mano de estas tres hermanas. Sus nombres son: Atropos, Clotho y Lachesis. Dícense Parcas por antífrasis, porque a ninguno perdonan, porque dicen que en naciendo el hombre hilan su vida en una rueca: Clotho da la estopa, o tiene la rueca; Lachesis la hila; Atropos corta el hilo. [...] Por esta ficción quisieron los antiguos declarar tres edades o tiempos, conviene saber: el tiempo en que nacemos y en el que vivimos, y el tiempo en que de la vida partimos; porque necesario es que todos los mortales estemos en uno destos tiempos. Por Clotho (que da la estopa, o tiene la rueca) se entiende el tiempo que en la vida entramos. Por Lachesis (que la hila) se entiende el tiempo que en la vida permanecemos. Por Atropos, que corta el hilo, se entiende el tiempo que della salimos, que es la muerte, y a esta dicen inexorable, o inmutable; porque no bastan ruegos para que no se corte el hilo de la vida del hombre, cuando Dios manda que muera. ${ }^{21} »$

Como vemos, las Parcas tienen en sus manos el destino de los hombres, aunque a Pérez de Moya se le haga necesario apostillar el mandato superior de Dios.

Nos interesa, no obstante, retroceder en las fuentes, aun a sabiendas de que no tengan en el texto calderoniano una relación directa con el tema, pues creemos que la aparición en el mismo texto de la figura de las Sirenas junto al de las Parcas formaba parte de una convención barroca de orígenes neoplatónicos que remitía a aspectos musicales que se ocultaban en el ideario de este tipo de obras. Al mencionar esto nos referimos al

\footnotetext{
19 Pérez de Moya, 1995: 215-216.

20 Bonnefoy, vol. 2, 1996: 178.

${ }^{21}$ Pérez de Moya, 1995: 639-640.
} 
fragmento de la República de Platón, en el que encontramos como parte del mito de Er, la siguiente explicación:

«En lo alto de cada uno de los círculos estaba una sirena que giraba junto con el círculo y emitía un solo sonido de un solo tono, de manera que todas las voces, que eran ocho, concordaban en una armonía única. Y había tres mujeres sentadas en círculo a intervalos iguales, cada una en su trono; eran las Parcas, hijas de la Necesidad, vestidas de blanco y con guirnaldas en la cabeza, a saber, Láquesis, Cloto y Atropo, y cantaban en armonía con las sirenas: Láquesis las cosas pasadas, Cloto las presentes y Atropo las futuras. ${ }^{22}{ }_{\text {» }}$

Ambos grupos de personajes, Sirenas y Parcas, conectan a través del mito platónico que después desarrollarán Macrobio, Boecio, Ficino, Zarlino, Kepler y otros muchos, con la música de las esferas y conceptos como el de música mundana, que tan recurrentes serán en la obra de Calderón, como pusiera de relieve Louise Stein ${ }^{23}$.

El último de los grupos de procedencia mitológica que aparece en la obra de Calderón es el de los cíclopes que labran las armas de Cupido en la fragua de Vulcano. El texto tiene carácter coral cantado y está compuesto por cuatro versos, tres de los cuales se repiten a modo de ritornello en varias ocasiones. En ningún momento se les ve en escena, y en las ediciones de 1664 no se les nombra en las acotaciones. Por otro lado, de los tres cíclopes hijos de Urano: Arges (luminoso), Brontes (estruendoso) y Esteropes (resplandeciente), sólo se menciona en el texto a los dos últimos. Baltasar de Vitoria en el Teatro de los dioses de la gentilidad nos dice:

«Tuvo también Saturno otros hermanos, que se llamaron Cíclopes, como lo dice Natal Comité, y Hesíodo, y fueron hijos del Cielo y de la Tierra [...] Estos fueron oficiales de Vulcano en sus herrerías, y forjaron los rayos para Júpiter [...] De sus nombres y de su oficio hizo memoria Virgilio en el libro 8 de la Eneida:

ferrum exercebant uasto Cyclopes in antro,

Brontesque Steropesque et nudus membra Pyragmon.

Lo mismo dice Ravisio Textor y añade que estos hicieron los rayos a Júpiter en la isla de Lypara, que allí tenían ellos su fragua y su habitación, y que en la isla de Creta fueron los primeros que hallaron la invención de la herrería. ${ }^{24}{ }$

Como vemos, lo que se resalta de los cíclopes son sus cualidades como artesanos que fraguan los rayos que Zeus utilizará, aunque también el propio Vitoria señale su capacidad como constructores.

La desviación en el texto de Calderón del uso del rayo por parte de Cupido y no de Júpiter está justificada por el propio argumento de la obra y tiene un antecedente ilustre

22 República, 2007: 497.

${ }^{23}$ Stein apuntaba lo siguiente: «The concept of música mundana was obviously not new in Calderón's time, and neither was the simbolic association between the music of the spheres and earthly concord. The scientific and philosophical theories concerning música mundana, which associated music divine power and with the hidden, perfect harmony of the universe, were developed by the ancient Greeks, elaborated upon in later Roman writings, and finally filtered through the sixteenth-century humanists. There are numerous poetic elaborations on this idea, tied to theories about the power of music, in Spanish poetry of the sixteenth and seventeenth centuries, so that the music of the spheres was still a vital idea in Calderón's time.» Stein, 1993: 118.

${ }^{24}$ Baltasar de Vitoria, De Saturno, 5. 
en este tipo de piezas de carácter operístico, pues Lope de Vega utilizó un motivo similar en La selva sin amor, en la que el dios del amor utilizaba las flechas fraguadas en el taller de Vulcano para distribuir oro o plomo.

\section{LOS DIOSES DE LOS GENTILES}

Por último, hay que mencionar el tercero de los niveles en el que la presencia de lo clásico se deja notar a través de los personajes de la obra: el de los dioses.

Desde el mismo título nos encontramos con una referencia al que es quizá el dios pagano más nombrado en la Literatura occidental barroca, pues la estructura coordinada trimembre del sintagma La fiera, el rayo y la piedra es una referencia directa a Cupido. Esta identificación del personaje con sus características probablemente la extrajo Calderón, como apunta Aurora Egido ${ }^{25}$, de la Agudeza y arte de ingenio de Gracián, en cuyo discurso XXXIX, titulado De los problemas conceptuosos y cuestiones ingeniosas podemos leer lo siguiente:

«La contrariedad de las respuestas tiene la misma gracia y relevante artificio, porque con su variedad suspende más el discurso, hasta que se vienen a unir y concordar en un sujeto con su moralidad y sentencia. Ingeniosamente introduce Falcón a Venus, que estando preñada preguntó a las Parcas qué había de parir. Láquesis dijo que un tigre; Cloto, que un pedernal; Átropos, que un rayo; y parió al amor, que lo es todo.

\section{Alma Venus pregnans, cum jam prope partus adesset, Consuluit Parcas, quid paritura foret? \\ Tigrim ait Lachesis; Silicem, Cloto; Atropos, Ignem; Ne responsa forent irrita, natus Amor.}

Corta al principio, y después ata, en que consiste el agradable desempeño. Don Manuel Salinas traduce así:
Preñada Venus un día, estando el parto vecino, al Oráculo Divino consultó qué pariría.
Tigre, Láquesis decía, Cloto, pedernal, y Fuego
Átropos; cumplióse luego, Pues porque respuestas tales fueran en verdad iguales, nació de Amor el dios ciego. ${ }^{26}$ »

Es un lugar común del teatro barroco la idea del dios del amor como desencadenante de males diversos, pero también como pretexto para el argumento de textos de base mitológica y trasfondo moral. Por lo general, la oposición entre el amor casto, o correspondido como se dice en el texto calderoniano, y el amor voluptuoso se simbolizan a través de Diana o alguna de sus ninfas como Dafne, el primero, y en las figuras de Venus

\footnotetext{
25 EGIDO, 1989: 55-56, n. 96

26 Gracián, 1993: 620.
} 
o Cupido el segundo. Sin embargo, en la obra calderoniana el dualismo entre el amor casto y el amor libidinoso lo representan Cupido (Eros) y Anteros, mientras que la diosa Venus ejerce de madre que intenta mediar entre la disputa de sus dos hijos.

Las connotaciones de Cupido son evidentes en la literatura renacentista y barroca y sus representaciones icónicas recogidas en los libros de emblemas y de exégesis alegórica, como los de Alciato o Ripa, instalaron la figura del dios en un lugar común de la retórica europea a través de sus diversas equivalencias, visuales y textuales ${ }^{27}$.

Menos común es la presencia de Anteros en la literatura del siglo XVII. Aunque no es difícil seguir su rastro a través de las huellas de su hermano, el dios del amor, según podemos leer en Baltasar de Vitoria:

«Siendo ya muy del cuidado de las Gracias el criar a Cupido, pusieron mucha diligencia en aquel cuidado; pero importó poco, porque al no tener el Amor otro niño de su edad con quien divertirse alegre, pasaba tristes los días creyendo desgraciada soledad aun la compañía de las Gracias. [...] Sembró la diosa Venus tiernos afectuosos cariños en fecunda tierra de los amores de Marte y cogió por fruto a Anteros, que significa Amor mutuo, igual afecto y correspondida fineza. Al ver el Amor a su hermano Anteros, alegróse gozoso, transformando en alegrías sus tristezas, en bienes sus males, en glorias sus penas y en alegres deliciosos regocijos sus siempre penosos descontentos.»

Pero surgen las disputas entre los dos hermanos por saber cuál de los dos es el verdadero amor, como también señala Vitoria:

«Es el dios Anteros Amor, que corresponde fino a quien con fineza le ama. Vincencio Cartario trae en su curioso libro de las imágenes de los dioses una imagen de lo que decimos. Pinta a Cupido con una palma en sus manos, y al dios Anteros, que en amorosa batalla anhelando glorioso triunfo, le procura quitar la palma para coronarse con la victoria. Intenta mostrar Cartario, Cupido, Dios del Amor, quiere tener la palma en el amar, y Anteros se la quiere quitar alentado, porque más que amar fino, es corresponder amante.»

Asimismo, se relaciona a Anteros con la historia de Meles y Timágoras, como también apunta Vitoria y cuenta Luc Brisson:

«Anteros, un personaje enigmático cuyo nombre parece que tiene que entenderse como el Amor correspondido. En Atenas, este hijo de Afrodita (la segunda, es decir, la hija de Zeus y Dione) y Ares (Cicerón, De natura deorum, III 60) tenía elevados sobre la Acrópolis una estatua y un santuario en memoria de dos jóvenes, Meles y Timágoras. Timágoras, un meteco, amaba a Meles, un ciudadano que menospreciaba su amor y que, para poner a prueba ese amor, le pidió a Timágoras que se arrojara desde lo alto de la Acrópolis. Timágoras lo hizo y, lleno de remordimientos, Meles se suicidó del mismo modo (Pausanias, I 30, 1). Con Anteros,

27 Son frecuentes las alusiones a Cupido como el dios niño, así como a su ceguera, al llevar los ojos vendados, como también son frecuentes los usos retóricos de los instrumentos que utiliza el dios, el arco y las flechas de oro y plomo. Como se lee en el Teatro de los dioses de la gentilidad: «Desnudo, alado, con arco y flechas dibujaron al amor los que más bien lo pintaron: estos fueron los amantes; y aunque finos le pintaron como quisieron, no fue pintar como querer, sino a razón ajustados.» Suma de las características del dios es la décima de Francisco de la Torre, que recoge en su obra Baltasar de Vitoria y que dice así: «Es niño Amor, porque alhaga,/ y crece toda la vida;/ con flechas, porque es herida;/ y con venda porque es llaga./ Desnudo porque le estraga/ la ficción; cisne con pluma/ porque muere, y canta en suma;/ y descendiente luz bella,/ porque es fuego de la estrella,/ porque es aire de la espuma.» 
Eros encuentra, pues, la reciprocidad que el Amor implica en todos los niveles en los que se ejerce su poder, y sea cual sea la naturaleza que se le asigne. ${ }^{28}$ »

\section{LOS DIVERSOS NIVELES DE UTILIZACIÓN DE LAS FUENTES CLÁSICAS}

Como hemos podido apreciar, las fuentes clásicas de la obra calderoniana parten del propio título, y por extensión, tienen un papel fundamental en la trama argumental. Asimismo, determinan el desarrollo de la acción a través de personajes de procedencia mitológica grecolatina, que, aunque se basan en fábulas distintas entre sí, otorgan al tema central un armazón ideológico y conceptual de gran cohesión, a pesar de la aparente dispersión de anécdotas.

No obstante, esta presencia, que podríamos denominar cuasi integral, de la materia clásica no se limita a la utilización retórica de una serie de recursos establecidos como lugares comunes para los autores y el público palaciego de las representaciones calderonianas, sino que se imbrica en el texto a través de diversos niveles de utilización de las fuentes grecolatinas, de los que destacaríamos fundamentalmente tres:

El primero de ellos tendría un carácter puramente retórico y en él el sólo uso de un nombre grecolatino tendría un sentido y una justificación como tópica literario sustentado en convenciones como los atributos de Cupido, la naturaleza de las Parcas y los Cíclopes o el canto de las Sirenas, así como la identificación de historias instaladas en la memoria receptora del público barroco con determinadas ideas, como la fábula de Pigmalión o de Anajarte ${ }^{29}$.

En un segundo nivel deberíamos hablar de la utilización de la materia mitológica clásica como instrumento para transmitir ideas de carácter moral y doctrinario, que es donde se situaría el núcleo temático de la obra, con la lucha entre el amor correspondido y el amor libidinoso, y el desenlace de Anajarte, convertida en estatua al negarse a amar.

Es cierto, en la línea de lo que se ha señalado en repetidas ocasiones, que el «sustrato amoroso», como lo llamó Aurora Egido, está en la base de las comedias mitológicas calderonianas, y nosotros lo haríamos extensible a gran parte de la producción de carácter operístico, y por extensión del teatro palaciego, pero pensamos que habría que matizar el concepto de 'lo amoroso' como tema, pues en la mayoría de los casos estamos hablando de una visión moralista que enfrenta dos formas muy distintas de abordar la materia y que tiene un carácter marcadamente sincrónico.

${ }^{28}$ Luc Brisson, en Bonnefoy, 1996: 374. Pausanias, como indica Brisson, en su Descripción de Grecia, narra el hecho del que parte la relación del dios con el amor correspondido, pues los metecos (extranjeros, no atenienses domiciliados en Atenas) hicieron la ofrenda pues consideraban a «Anteros como el espíritu vengador de Timágoras.» Pausanias, 2009: 87.

${ }_{29}$ Al mencionar el carácter retórico de un escrito somos conscientes de la inexactitud y falta de delimitación teórica, por lo que preferimos completar nuestra idea con las palabras de unos de los especialistas mayores en el tema: «Sabido es que la retórica ocupa un lugar preeminente en el sistema educativo antiguo y medieval, y que su importancia entre las disciplinas humanísticas fue crucial hasta el advenimiento del Romanticismo. El método de aprendizaje de la disciplina, desde la Antigüedad, implica tres procesos complementarios: el estudio de los preceptos, la imitación de modelos y la praxis personal (Rhetorica ad Herennium, I, 2, 3). » (Azaustre/ Casas, 2004: 10). 
Y en dicho carácter sincrónico juega un papel fundamental el público al que iba dirigido este tipo de espectáculos, que no era otro que la monarquía, por lo que es necesario cuidar todos los aspectos de la creación, y de un modo además que no revele que se está instruyendo a los espectadores reales y no sólo divirtiéndolos, como apunta Bances Candamo:

«Son las comedias de los reyes unas historias vivas que, sin hablar con ellos, les han de instruir con tal respeto que sea su misma razón quien de lo que ve tome las advertencias, y no el Ingenio quien se las diga. Para este decir sin decir, ¿quién dudará que sea menester gran arte? Porque harto peligrosa es la discreción, que da más aplauso al que la sufre que al que la dice. Conviene a los Príncipes oír los sucesos pasados más que a otros hombres, porque hallen en ellos la verdad que nadie se atreve a decirles. ${ }^{30} \gg$

La elección de la materia mitológica sobre la que se sustenta la trama la realiza Calderón con la plena conciencia de que no sólo debía ofrecer al monarca un espectáculo que le divirtiera, sino también, y sobre todo, un ejemplo que contribuyera a su educación, sin que por ello se hiciera evidente tal hecho, aunque hubiera una innegable relación especular entre los mundos mostrados y los vividos por aquellos que asistían a la representación ${ }^{31}$.

Por último, deberíamos hablar de un tercer nivel de análisis, más profundo y con un recorrido diacrónico evidente por su trasfondo universal. En él situaríamos el origen conceptual del enfrentamiento entre Cupido y Anteros, base de una forma de interpretar el mundo desde una perspectiva marcadamente barroca.

Nos deberíamos retrotraer a la castración de Urano, aunque parezca una afirmación alejada supuestamente de nuestro tema, pues cuando el sexo del dios es arrojado por Cronos una parte de la sangre fecunda la tierra negra, de donde surgen las Erinias, los Gigantes y las ninfas de los fresnos, y los genitales de Urano llegan al mar y se mezclan con la espuma, de la que nace Afrodita, que llegará a Chipre acompañada de Amor y Deseo. Como sostiene Vernant:

«La castración de Urano engendra, pues, en la Tierra y el Mar, dos órdenes de consecuencias que son inseparables a pesar de su oposición: por un lado, violencia, odio, guerra; por otro, dulzura, acuerdo, amor. [...] El mundo se organizará, pues, a través de la mezcla de los contrarios y la mediación entre los opuestos. Pero en este universo mixto, en el que se equilibran potencias de conflicto y potencias de armonía, la línea divisoria no se establece entre el bien y el mal, entre lo positivo y lo negativo. Las fuerzas de la guerra y las del amor tienen igualmente aspectos claros y aspectos oscuros, aspectos benéficos y maléficos. La relación de tensión que las mantiene separadas las unas de las otras se manifiesta también dentro de cada una de ellas en forma de polaridad, de una ambigüedad inmanente a su propia naturaleza. ${ }^{32}$ »

\footnotetext{
30 Bances, 1970: 57.

${ }^{31}$ Como apunta Luciana Gentilli: «Lo schermare la verità attraverso i filtri del diletto, dell'espressione ambigua e dell'enigma sofisticato crea un modello di comunicazione che aderisce perfettamente al cerimoniale cortigiano. I criteri metodologici che ispirano la didattica dell'educazione del monarca sono difatti inscritti nella strategia della discrezione e del convincimento garbato.» (Gentillli, 1991: 37)

32 Jean Pierre Vernant, en Bonnefoy, Diccionario de las mitologías, vol. II, 1996: 102-103.
} 
Es aquí donde tiene su origen el dualismo calderoniano en particular, y barroco en general, de forma directa o indirecta, ligado a la materia amorosa como motor que mueve la vida de los personajes y las acciones de gran parte de las obras dramáticas de carácter operístico.

Asimismo, en este tercer nivel de utilización de la materia clásica por parte de Calderón se situaría la concepción del mundo del autor madrileño, y hasta podríamos decir del universo. Ahí ubicaríamos las ideas neoplatónicas, tan importantes en un género como el teatro de carácter operístico, en el que la teoría de la armonía de las esferas como ordenación del caos parte del concepto de lo musical, y por extensión de lo artístico, como auténtico motor del engranaje que mueve el mundo ${ }^{33}$.

Como hemos podido comprobar, la utilización de la materia clásica cobra en Calderón una complejidad acorde a sus planteamientos literarios y escénicos. Y al igual que sucede en el plano espectacular, en el que es fundamental la conjunción y perfecto ensamblaje de elementos como el propio texto, la escenografía, la música y el movimiento, en la composición, estructura y conceptualización de la fábula es necesaria una perfecta adecuación de la materia al estilo, la forma y la recepción de la obra.

Nos aventuramos a decir que Calderón era un maestro como autor en el doble sentido de este término, el sincrónico, es decir, en su acepción de director escénico, y el diacrónico, como creador de realizaciones artísticas. Y en ambos aspectos, el bagaje cultural y conceptual clásico dotaron a sus textos de un carácter universal, que sólo aquellos genios de primera clase son capaces de conferir a sus creaciones a todos los niveles.

\section{BIBLIOGRAFÍA}

Apolodoro (1982). Biblioteca, trad. de M. Rodríguez de Sepúlveda, Madrid, Gredos.

Azaustre, Antonio / Casas, Juan (2004). Manual de retórica española, Barcelona, Ariel.

Bances Candamo, Francisco (1970). Theatro de los Theatros de los passados y presentes siglos, ed. de D. W. Moir, Londres, Tamesis Books.

Bonnefoy, Ives (1996). Diccionario de las mitologías, vol. II. Grecia, Barcelona, Destino.

Bustamante, Jorge (1595). Las transformaciones de Ovidio en lengua española, Google Books.

Calderón de la Barca, Pedro (1989). La fiera, el rayo y la piedra, ed. Aurora Egido, Madrid, Cátedra.

EgIDO, Aurora (1989). «Introducción y edición de La fiera, el rayo y la piedra de Calderón de la Barca», Madrid, Cátedra.

Gentilli, Luciana (1991). Mito e spettacolo nel teatro cortigiano di Calderón de la Barca. Fortunas de Andrómeda y Perseo, Roma, Bulzoni.

Gracián, Baltasar (1993). Agudeza y arte de ingenio, Madrid, Turner.

${ }^{33}$ Ana Suárez explica con maestría la correspondencia entre las esferas escénicas y la dualidad conceptual calderoniana: «Es evidente que el teatro de Calderón nos ofrece un desarrollo completo de la estructura esférica mediante gradaciones, que a modo de círculos sucesivos, se van abriendo en la mente del espectador. Para ello, parte de un juego de bóvedas iniciales que representan la tierra y el cielo y que sólo unidas (esfera) adquieren la perfección. La tensión dramática consiste en alcanzar esa unidad y por ello, aunque su teatro está repleto de dramatismo, el sentido final es positivo. Si esas dos bóvedas son las grandes estructuras cósmicas, todas las posibilidades de expresión del ser humano se construyen de forma paralela, y el autor se encarga de recordarnos continuamente el carácter dual de todo lo existente, así como sus correspondencias entre las dos esferas extremas.» (Suárez, 2001: 270). 
Ovidio (1982). Metamorfosis, ed. Ruiz de Elvira, Madrid, Gredos.

Pausanias (2009). Descripción de Grecia, Madrid, Gredos.

Platón (2007). República, Madrid, Gredos.

PÉrez de Moya, Juan (1995). Philosophia secreta, ed. C. Clavería, Madrid, Cátedra.

Stein, Louise K., (1993). Songs of mortals, dialogues of the gods, Oxford, Clarendon Press.

SuÁreZ, ANa (2000). «La correspondencia de las esferas en el universo de Calderón», en Calderón de la Barca y su aportación a los valores de la cultura europea: 14 y 15 de noviembre de 2000/ Jornadas internacionales de Literatura Comparada, Madrid, San Pablo-CEU.

Virgilio (2007). Eneida, Madrid, Gredos.

Vitoria, Baltasar de (1702). Teatro de los dioses de la gentilidad, Google Books. 